Editorial

\title{
Feature Papers in Magnetochemistry
}

\author{
Carlos J. Gómez-García (1)
}

Citation: Gómez-García, C.J.

Feature Papers in Magnetochemistry.

Magnetochemistry 2021, 7, 48.

https: / / doi.org/10.3390/

magnetochemistry7040048

Received: 1 April 2021

Accepted: 1 April 2021

Published: 2 April 2021

Publisher's Note: MDPI stays neutral with regard to jurisdictional claims in published maps and institutional affiliations.

ICMol, Departamento de Química Inorgánica, Universidad de Valencia, Catedrático José Beltrán 2, 46980 Paterna, Spain; carlos.gomez@uv.es; Tel.: +34-9-6354-4423; Fax: +34-9-6354-3273

\section{Introduction}

When we launched the journal Magnetochemistry in 2015 we could not imagine such an enthusiastic response from the scientific community. After only five years, thanks to the high level of the contributors and their contributions, Magnetochemistry is recognized by many magneto-chemists and scientists working in this area as a journal of reference in the field of magnetochemistry. A proof of this acceptation is the number of articles published to date and its increasing trend: a total of 340 articles have been published so far in seven volumes of Magnetochemistry with a clear increasing trend, as can be seen in Figure 1. The figures in 2021 are much better since the total number of published articles in January and February, results in an extrapolated value of more than 160 for 2021 (for a detailed statistical study, visit the webpage: https:/ /www.mdpi.com/journal/magnetochemistry/ stats, accessed on 28 March 2021).

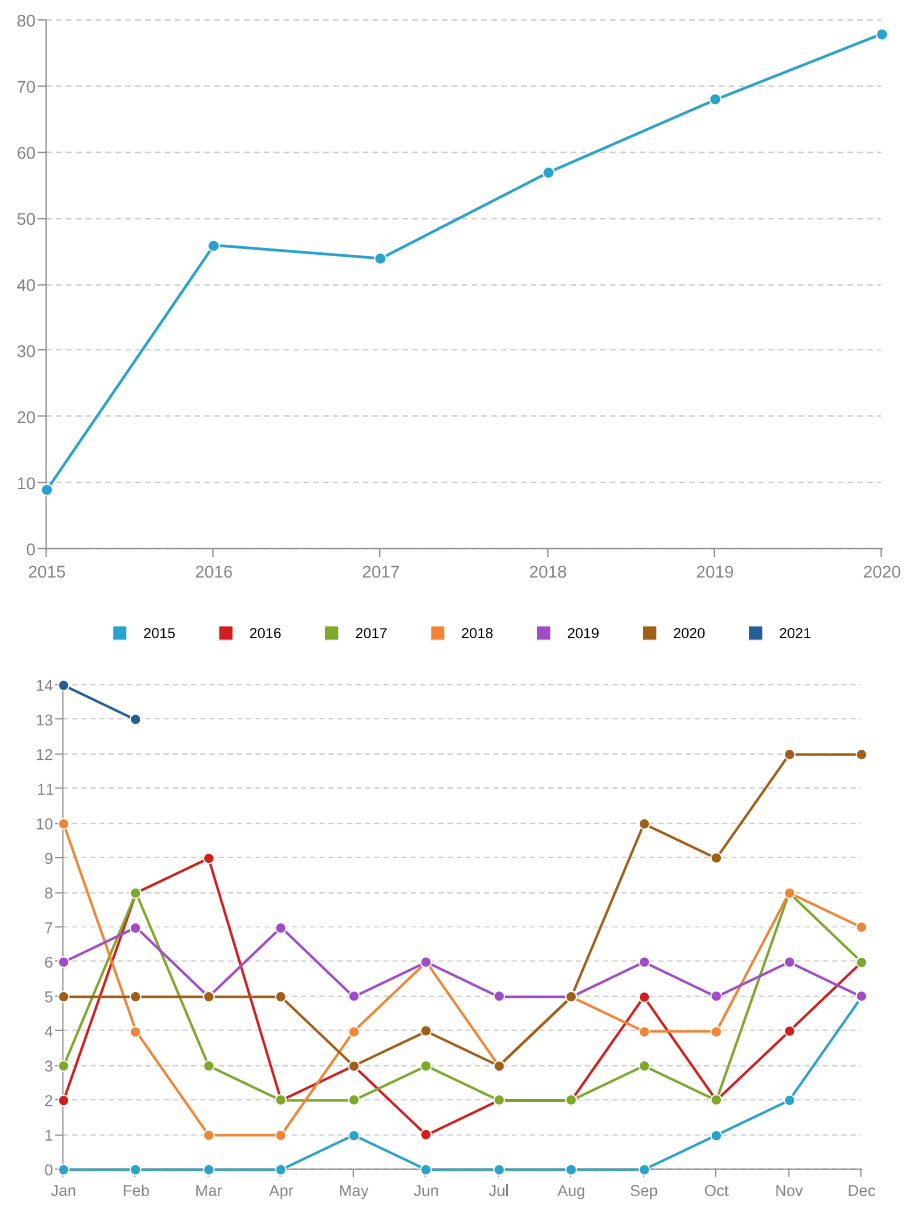

Figure 1. Yearly (above) and monthly (below) published articles in Magnetochemistry. 
The journal was indexed by the Emerging Sources Citation Index-Web of Science in 2016, by the Science Citation Index Expanded (SCIE) in 2019, and by Scopus in 2020. Finally, in 2020, the Journal Citation Report assigned Magnetochemistry an impact factor of 1.947, which placed the journal in Q2 category rank in the area "Chemistry, Inorganic and Nuclear". This was very good news, and we hope to further improve in 2021.

To celebrate the fifth anniversary of the journal and to thank our many contributors, in 2020 we launched a Special Issue with feature articles in magnetochemistry. The result is this Special Issue, where a total of eleven contributions show the landscape of the discipline. These contributions include feature, perspective, regular, and review articles covering different aspects of the area.

The first contribution, by E. Yagubskii et al. [1] shows a very interesting combined structural and magnetic characterization of a series of mononuclear pentagonal bipyramidal Co(II) complexes with axial pseudohalide ligands. These complexes are field-induced single-ion magnets that show slow magnetic relaxation with dominant Raman and direct spin-phonon processes. The study includes ab initio calculations that reveal large, easy-plane magnetic anisotropies in all cases. The second contribution, by J. R. GalánMascarós et al. [2], reports a world record: the molecule-based chiral magnets with the highest ordering temperatures reported to date $\left(\mathrm{T}_{\mathrm{C}} \approx 255 \mathrm{~K}\right)$. These chiral magnets were prepared incorporating a chiral amino-acid such as L-proline or D-proline in vanadiumchrome Prussian blue derivatives. Interestingly, these chiral magnets show magnetic hysteresis, in contrast to the parent $\mathrm{V}\left[\mathrm{Cr}(\mathrm{CN})_{6}\right]_{x}$ room temperature magnets. The third contribution, by F. Pointillart et al. [3], reports the structural and magnetic characterization of two mononuclear Dy(III) complexes, showing single-molecule magnet behavior without any applied external DC magnetic field. In both Dy monomers, the magnetization relaxes through Orbach, Raman and Quantum Tunneling mechanisms (this latter process can be suppressed by the application of a DC magnetic field). The magnetic properties were rationalized by means of wavefunction theoretical calculations. The fourth contribution, by F. Lloret et al. [4], reports the structural and magnetic characterization of two mononuclear octahedral hexahalorhenate (IV) complexes formulated as $\left(\mathrm{PPh}_{4}\right)_{2}\left[\mathrm{ReX}_{6}\right](\mathrm{X}=\mathrm{Br}$ and I). Both complexes showed slow relaxation of the magnetization in the presence of external DC fields with higher energy barriers for the bromoderivative. The fifth contribution, by S. Triki et al. [5], presents two very rare examples of anionic spin crossover complexes in the series $\left[\mathrm{FeL}_{2}\right]\left[\mathrm{FeL}(\mathrm{NCS})_{3}\right]_{2} \cdot 2 \mathrm{CH}_{3} \mathrm{CN}$ (where $\mathrm{L}=$ tripodal chelating ligand and $\mathrm{E}=\mathrm{S}$ and $\mathrm{BH}_{3}$ ). Interestingly, these compounds are formed by cationic $\left[\mathrm{FeL}_{2}\right]^{2+}$ and anionic $\left[\mathrm{FeL}(\mathrm{NCE})_{3}\right]^{-}$complexes. The magnetic studies show the presence of a one-step transition with $\mathrm{T}_{\mathrm{C}} \approx 205 \mathrm{~K}$ for the $\mathrm{S}$ derivative and a two-step transition for the $\mathrm{BH}_{3}$ derivative centered at $\approx 245 \mathrm{~K}$ and $380 \mathrm{~K}$. The sixth contribution, by G. Molnár et al. [6], presents an interesting study of the pressure dependence of the electrical conductivity of nanocrystalline powder samples of the $\mathrm{Fe}(\mathrm{II})$ spin crossover complex [Fe(pyrazine) $\left.\left\{\mathrm{Au}(\mathrm{CN})_{2}\right\}_{2}\right]$. The aim is to control the conductivity by switching the spin state of the Fe(II) complex by applying an external pressure. The study shows that the conductivity is higher in the low spin state with a hysteresis that parallels the magnetic properties. Interestingly, the application of high pressures reduces the hysteresis and eventually cancels it for pressures above approximately 2 kbar. A possible structural transition may be at the origin of this rare phenomenon that is also sample-dependent. The seventh contribution, by B. Tsukerblat et al. [7], shows the effect of the double exchange in square-planar mixedvalence tetramers of the type $\mathrm{d}^{\mathrm{n}+1}-\mathrm{d}^{\mathrm{n}+1}-\mathrm{d}^{\mathrm{n}}-\mathrm{d}^{\mathrm{n}}$, with two excess electrons delocalized over four sites. They performed a detailed analysis of the simplest $d^{2}-d^{2}-d^{1}-d^{1}$ case to show that in this system, the double exchange produced by the delocalized electronic pair produces an antiferromagnetic spin alignment. This result contrasts with the ferromagnetic coupling produced by the double exchange in dimers and tetramers with only one excess electron or hole. This result is shown to be due to the antiparallel spin alignment of the two mobile electrons, resulting in an overall antiferromagnetic coupling. The authors also show that, depending on the relative strength of the second-order double 
exchange and the Heisenberg-Dirac-Van Vleck exchange, the system has either a groundlocalized spin-triplet or a ground-delocalized spin-singlet. The eighth contribution, by M. L. Mercuri et al. [8], is a perspective article on the design of magnetic nano-metal organic frameworks (nano-MOFs) for their use in different fields such as drug delivery, thermometry, theranostics, etc. The contribution summarizes the recent results in miniaturization processes to develop magnetic sub-micrometric or nanometric MOFs, presenting an overview of the current trends to design magnetic nano-MOFs in the field of biomedicine, with particular emphasis on theranostics and bioimaging. This contribution also shows the importance of the design of miniaturization processes to control the shape and size of the micro and nanoparticles while retaining their magnetic properties and high porosity. The ninth contribution, by P. Zielinski et al. [9], reports the effects of finite length on the switching mechanisms in chains formed by magnetic particles. These chains, which may support $\mathrm{GHz}$ spin waves, and their equilibrium configurations, crucial for such applications, can be switched by an external magnetic field. In this contribution, the authors study finite and infinite chains of magnetic particles with either ellipsoidal or rectangular shapes with long axes perpendicular to the chain axis and apply variable magnetic fields parallel to the long axes. Besides the main differences for the two types of chains, the authors discuss some practical consequences of their findings. The tenth contribution, by I. Shuttleworth [10], discusses the electronic band structures of the ordered $\mathrm{L}_{2}$ and $\mathrm{L1}_{0}$ phases of $\mathrm{Pt}_{\mathrm{x}} \mathrm{M}_{1-\mathrm{x}}$ alloys $(\mathrm{M}=\mathrm{Fe}, \mathrm{Co}$, and $\mathrm{Ni}$ ), determined using spin-polarized DFT. The study determines the relative contributions of itinerant and localized magnetism at the high-symmetry $k$-points and shows important directional effects of the $\mathrm{L} 1_{0}$ and $\mathrm{L} 1_{2}$ alloys, which are discussed in terms of charge channeling effects. The final contribution, by $\mathrm{S}$. Benmansour and myself (C. J. Gómez-García) [11], is a review describing the structurally characterized complexes containing lanthanoids (including La and group 3 metals: Y and $\mathrm{Lu}$ ) and any anilato-type ligand (3,6-disubstituted-2,5-dihydroxy-1,4-benzoquinone dianion $\left.=\mathrm{C}_{6} \mathrm{O}_{4} \mathrm{X}_{2}{ }^{2-}\right)$. The review includes those compounds containing other ligands and/or coordinated solvent molecules (besides the anilato-type ligands). The contribution revises all the structural types observed in these compounds (from discrete monomers, dimers, and tetramers to extended 1D, 2D, and 3D lattices with different topologies), as well as their characteristics such as: magnetic properties (including single-molecule and single-ion magnet behaviors, SMM and SIM), luminescence, electrochemistry, gas/solvent absorption and exchange capacity. Finally, the revision shows some attempts performed to prepare thin films of these compounds.

Last, but not least, I would like to thank all the authors for providing such interesting contributions, the reviewers for their helpful comments that improved the quality of the contributions, and the editorial staff of Magnetochemistry and MDPI for their fast and diligent work. I hope that you will enjoy these contributions and find them useful reference points.

Conflicts of Interest: The authors declare no conflict of interest.

\section{References}

1. Kopotkov, V.A.; Korchagin, D.V.; Sasnovskaya, V.D.; Gilmutdinov, I.F.; Yagubskii, E.B. A Series of Field-Induced Single-Ion Magnets Based on the Seven-Coordinate $\mathrm{Co}(\mathrm{II})$ Complexes with the Pentadentate $\left(\mathrm{N}_{3} \mathrm{O}_{2}\right) \mathrm{H}_{2}$ dapsc Ligand. Magnetochemistry 2019, 5, 58. [CrossRef]

2. Rodríguez-García, B.; Galán-Mascarós, J.R. Spontaneous Magnetization and Optical Activity in the Chiral Series (LProline $)_{\mathrm{n}} \mathrm{V}\left[\mathrm{Cr}(\mathrm{CN})_{6}\right]_{\mathrm{x}}(0<\mathrm{n}<3)$. Magnetochemistry 2020, 6, 12.

3. Galangau, O.; Flores Gonzalez, J.; Montigaud, V.; Dorcet, V.; le Guennic, B.; Cador, O.; Pointillart, F. Dysprosium Single-Molecule Magnets Involving 1,10-Phenantroline-5,6-Dione Ligand. Magnetochemistry 2020, 6, 19. [CrossRef]

4. Rojas-Dotti, C.; Sanchis-Perucho, A.; Orts-Arroyo, M.; Moliner, N.; González, R.; Lloret, F.; Martínez-Lillo, J. Field-Induced Single-Ion Magnet Phenomenon in Hexabromo- and Hexaiodorhenate(IV) Complexes. Magnetochemistry 2020, 6, 20. [CrossRef]

5. Cuza, E.; Benmansour, S.; Cosquer, N.; Conan, F.; Pillet, S.; Gómez-García, C.J.; Triki, S. Spin Cross-Over (SCO) Anionic Fe(II) Complexes Based on the Tripodal Ligand Tris(2-pyridyl)ethoxymethane. Magnetochemistry 2020, 6, 26. [CrossRef] 
6. Gheorghe, A.; Bibik, Y.S.; Kucheriv, O.I.; Barakhtii, D.D.; Boicu, M.; Rusu, I.; Diaconu, A.; Gural'skiy, I.A.; Molnár, G.; Rotaru, A. Anomalous Pressure Effects on the Electrical Conductivity of the Spin Crossover Complex $\left[\mathrm{Fe}(\mathrm{Pyrazine})\left\{\mathrm{Au}(\mathrm{CN})_{2}\right\}_{2}\right]$. Magnetochemistry 2020, 6, 31. [CrossRef]

7. Palii, A.; Clemente-Juan, J.M.; Aldoshin, S.; Korchagin, D.; Golosov, E.; Zilberg, S.; Tsukerblat, B. Can the Double Exchange Cause Antiferromagnetic Spin Alignment? Magnetochemistry 2020, 6, 36. [CrossRef]

8. Oggianu, M.; Monni, N.; Mameli, V.; Cannas, C.; Ashoka Sahadevan, S.; Mercuri, M.L. Designing Magnetic NanoMOFs for Biomedicine: Current Trends and Applications. Magnetochemistry 2020, 6, 39. [CrossRef]

9. Kuźma, D.; Zieliński, P. Finite Length Effects on Switching Mechanisms in Chains of Magnetic Particles. Magnetochemistry 2020, 6, 47. [CrossRef]

10. Shuttleworth, I. The Magnetic Band-Structures of Ordered $\mathrm{Pt}_{\mathrm{x}} \mathrm{Fe}_{1-\mathrm{x}}, \mathrm{Pt}_{\mathrm{x}} \mathrm{Co}_{1-\mathrm{x}}$, and $\mathrm{Pt}_{\mathrm{x}} \mathrm{Ni}_{1-\mathrm{x}}(\mathrm{x}=0.25,0.50$, and 0.75). Magnetochemistry 2020, 6, 61. [CrossRef]

11. Benmansour, S.; Gómez-García, C.J. Lanthanoid-Anilato Complexes and Lattices. Magnetochemistry 2020, 6, 71. [CrossRef] 